\title{
Valor Nutritivo das Leveduras de Recuperação (Saccharomyces sp), Seca por Rolo Rotativo ou por "Spray-Dry", para Coelhos Em Crescimento"
}

\author{
Haroldo Garcia de Faria², Cláudio Scapinello³, Antonio Cláudio Furlan³, Ivan Moreira ${ }^{3}$, \\ Elias Nunes Martins ${ }^{3}$
}

\begin{abstract}
RESUMO - Foram utilizados 30 coelhos da Raça Nova Zelândia Branco, 15 machos e 15 fêmeas, com 50 dias de idade, em um ensaio de digestibilidade, com o objetivo de determinar o valor nutritivo das leveduras de recuperação (Saccharomyces sp), seca em rolo rotativo (LRRR) e por spray-dry (LRSD). Os coelhos foram distribuídos em um delineamento inteiramente casualizado com três tratamentos e dez repetições, sendo uma dieta referência e duas dietas teste. Na elaboração das dietas testes, a LRRR e a LRSD substituíram, respectivamente, $25 \%$ da matéria seca da dieta referência contendo 15,27\% de proteína bruta, 15,51\% de fibra bruta e $4397 \mathrm{kcal}$ de energia bruta. Os coeficientes de digestibilidade aparente da matéria seca, proteína bruta, fibra bruta e energia bruta, foram, respectivamente, de 73,80; 55,44; 55,27; e 69,60\% para LRRR e 82,33;79,14;48,24; e 87,19\% para a LRSD. Os teores de matéria seca digestível, proteína digestível, fibra bruta digestível e energia digestível, com base na matéria seca total, foram, respectivamente, de $68,06 \%, 18,25 \%, 0,80 \%$ e $3248 \mathrm{kcal} / \mathrm{kg}$ para a LRRR e de 75,57\%, 25,22\%, 0,20\% e $3859 \mathrm{kcal} / \mathrm{kg}$ para a LRSD. Os resultados indicaram que a LRSD apresentou-se nutricionalmente melhor que a LRRR.
\end{abstract}

Palavras-chave: coelhos, digestibilidade, levedura de recuperação

\section{Nutritional Value of Recovery Yeast (Saccharomyces sp), Dried by Rotative Cylinder or by "Spray-Dry" For Growing Rabbits}

\begin{abstract}
Thirty rabbits from New Zealand White breed , 15 males and 15 females, with 50 days of age, were used on assay of digestibility, with the aim to determine the nutritional value of recovery yeast (Saccharomyces sp), dried in a rotational cylinder (RYRC) and by spray-dry (RYSD). The rabbits were assigned to a completely randomized experimental design with three treatments and ten replicates, with one as a reference diet and two test diets. In the elaboration of test diets, the RYRC and the RYSD replaced $25 \%$ of the reference diet dry matter, containing $15.27 \%$ of crude protein, $15.51 \%$ of crude fiber, and 4397 kcal of gross energy, respectively. The coefficients of apparent digestibility of dry matter, crude protein, crude fiber, and gross energy were, $73.80 \%$, $55.44 \%, 55.27 \%$ and $69.60 \%$ for RYRC and $83.33 \%, 79.14 \%, 48.24 \%$ and $87.19 \%$, respectively, for RYSD. The dry matter digestible, crude protein digestible, crude fiber digestible and gross energy digestible, based on the total dry matter were, $68.06 \%, 18.25 \%, 0.80 \%$ and 3,448 kcal/kg for RYRC and 75.57\%, 25.22\%, $0.20 \%$ and 3,858\% kcal/kg, respectively, for RYSD. The results showed that RYSD was nutritionally better than RYRC.
\end{abstract}

Key Words: digestibility, rabbit, recovery yeast

\section{Introdução}

Muitas pesquisas na área de nutrição animal têm sido direcionadas para a substituição de fontes convencionais de nutrientes por fontes alternativas. Esse procedimento visa, principalmente, a redução dos gastos com alimentação. Porém, outras vantagens podem ser citadas, como menor competição com homem em relação aos alimentos de uso comum e eliminação ou redução de subprodutos poluentes (FAZANO, 1986). Também, segundo MIYADA (1987), há necessidade de se descobrirem novas alternativas de uso destes produtos e subprodutos, procurando otimizar seu emprego e ampliar o conjunto de conhecimentos e técnicas existentes, por meio de enfoques fisiológicos e metabólicos da nutrição e alimentação, bem como conhecer as limitações de inclusão destas matérias-primas em rações para as diferentes categorias dentro de cada espécie animal.

Entre as fontes alternativas pesquisadas, grande atenção é dada aos microorganismos. Existem vários grupos de microorganismos considerados como fonte de proteína unicelulares, entre os quais se destacam as leveduras (DABBAH, 1970; KIHLBERG, 1972; e

\footnotetext{
${ }^{1}$ Projeto financiado pelo CNPq.

2 Zootecnista do Biotério Central - UEM Av Colombo 5790, CEP 87020-900, Maringá -PR.

3 Professor do Departamento de Zootecnia - UEM - Av Colombo 5790, CEP 87020-900, Maringá -PR. E.mail: cscapinello@uem.br
} 
YOURSI, 1982). Esse fato é de grande importância para o Brasil, tendo em vista o potencial de produção de levedura (Saccharomyces $s p$ ) pelas destilarias de álcool, que, após a secagem, pode ser usada na elaboração de rações para animais não-ruminantes, como suínos, aves e coelhos.

Poucos estudos foram realizados em coelhos com levedura do gênero Saccharomyces (PROENÇA et al., 1982; FAZANO, 1986; CARREGAL e FONSECA, 1990; e CARREGAL et al., 1990).

FAZANO (1986) determinou os coeficientes de digestibilidade da proteína do farelo de soja e da levedura seca (Saccharomyces sp), para coelhos com 40 dias de idade. Os coeficientes de digestibilidade da proteína foram de 86 e $87,7 \%$, respectivamente, para levedura seca e farelo de soja.

Trabalhando com níveis de inclusão de levedura em substituição ao farelo de soja para coelhos em crescimento, CARREGAL et al. (1990) constataram não haver diferenças nos coeficientes de digestibilidade da matéria seca, proteína bruta, fibra bruta e do extrato etéreo, indicando que as fontes de proteína testadas apresentaram valores nutricionais semelhantes.

O objetivo do presente trabalho foi determinar o valor nutritivo das leveduras de recuperação (Saccharomyces sp), secas por rolo rotativo (LRRR) ou por spray-dry (LRSD), para coelhos em crescimento, por meio de ensaio de digestibilidade.

\section{Material e Métodos}

Foram utilizados 30 coelhos da Raça Nova Zelândia Branco, 15 machos e 15 fêmeas, com 50 dias de idade, alojados, individualmente, em gaiolas de metabolismo providas de bebedouros automáticos, comedouros semi automáticos e dispositivos de coleta, em separado, de fezes e urina, em um delineamento inteiramente casualizado com três tratamentos e 10 repetições. Foram utilizadas três dietas, uma referência e duas teste, nas quais as leveduras provindas de diferentes indústrias e métodos de secagem (LRRR) e (LRSD) substituíram, respectivamente, $25 \%$ da matéria seca da ração referência.

A composição química das leveduras estudadas e a composição centesimal e química da dieta referência são mostradas, respectivamente, nas Tabelas 1 e 2.

$\mathrm{O}$ experimento teve duração de 14 dias, sendo sete dias para adaptação às rações e às gaiolas e sete dias para coleta de fezes. Durante a fase de adaptação, os animais receberam ração à vontade para obtenção do consumo voluntário. A média de consumo
Tabela 1 - Composição química das leveduras de recuperação (Saccharomyces sp), seca por rolo rotativo (LRRR) ou por "spray-dry"(LRSD), com base na matéria natural ${ }^{1}$

Table 1 - Chemical composition of recovery yeast (Saccharomyces $s p$ ) dried by rotational cylinder (RYRC) or by "spray-dry" (RYSD), as fed basis

\begin{tabular}{lccc}
\hline $\begin{array}{l}\text { Nutrientes } \\
\text { Nutrients }\end{array}$ & $\begin{array}{c}\text { Unidade } \\
\text { Unit }\end{array}$ & $\begin{array}{c}\text { LRRR } \\
\text { RYRC }\end{array}$ & $\begin{array}{c}\text { LRSD } \\
\text { RYSD }\end{array}$ \\
\hline $\begin{array}{l}\text { Matéria seca } \\
\text { Dry matter }\end{array}$ & $\%$ & 92,23 & 91,79 \\
$\begin{array}{l}\text { Proteína bruta } \\
\text { Crude protein }\end{array}$ & $\%$ & 30,35 & 29,25 \\
$\begin{array}{l}\text { Fibra bruta } \\
\text { Crude fiber }\end{array}$ & $\%$ & 1,34 & 0,38 \\
$\begin{array}{l}\text { Energia bruta } \\
\text { Gross energy }\end{array}$ & $\mathrm{kcal} / \mathrm{kg}$ & 4304 & 4062 \\
\hline
\end{tabular}

1 Análises realizadas no laboratório de nutrição do Departamento de Zootecnia da Universidade Estadual de Maringá.

1 Analyses carried out at the animal nutrition lab of Animal Science Departament of Maringá State University.

estabelecida na fase de adaptação foi fornecida durante o período de coleta, evitando-se, dessa forma, sobras nos comedouros. A temperatura média registrada no período experimental foi de $24,6^{\circ} \mathrm{C}$, sendo a máxima e a mínima de $27,5 \mathrm{e} 21,8^{\circ} \mathrm{C}$, respectivamente.

As fezes de cada animal foram coletadas em sua totalidade, no período da manhã, acondicionadas em sacos plásticos e armazenadas em freezer a $-10^{\circ} \mathrm{C}$. Posteriormente, ao final do experimento, as fezes de cada animal foram pesadas, homogeneizadas e colocadas em estufas de ventilação forçada a $60^{\circ} \mathrm{C}$, durante 72 horas. Em seguida, foram moídas e acondicionadas em vidros, devidamente identificados, para análises laboratoriais, de acordo com SILVA (1990).

Os coeficientes de digestibildade aparente da matéria seca (CDaMS), fibra bruta $(\mathrm{CDaFB})$, proteína bruta $(\mathrm{CDaPB})$ e energia bruta $(\mathrm{CDaEB})$, das leveduras foram obtidos utilizando a metodologia de MATTERSON et al. (1965). Para obtenção dos valores de nutrientes digestíveis, aplicaram-se os valores do coeficiente de digestibilidade sobre a composição química das leveduras.

O modelo estatístico utilizado para análise dos coeficientes de digestibilidade foi:

$$
\mathrm{Y}_{\mathrm{ij}}=\mu+\mathrm{L}_{\mathrm{i}}+\mathrm{e}_{\mathrm{ij}}
$$

em que $Y_{i j}$ é valor observado das variáveis estudadas, relativo a cada indivíduo $j$, recebendo a levedura $i ; \mu$, constante geral; $\mathrm{L}_{\mathrm{i}}$, efeito do tipo de levedura $i$, sendo $i=1$ e 2 e $i_{1}=$ LRRR e $i_{2}=$ LRSD; $\mathrm{e}_{\mathrm{ij}}$, erro aleatório associado a cada observação. 
1752 Rev. bras. zootec.

Tabela 2 - Composição centesimal e química da dieta referência

Table 2 - Chemical and percentage composition of the reference diet

\begin{tabular}{|c|c|c|}
\hline $\begin{array}{l}\text { Ingredientes } \\
\text { Ingredients }\end{array}$ & $\begin{array}{c}\text { Unidade } \\
\text { Unit }\end{array}$ & $\%$ \\
\hline $\begin{array}{l}\text { Milho } \\
\text { Corn }\end{array}$ & $\mathrm{kg}$ & 31,69 \\
\hline $\begin{array}{l}\text { Farelo de soja } \\
\text { Soybean meal }\end{array}$ & $\mathrm{kg}$ & 8,50 \\
\hline $\begin{array}{l}\text { Farelo de trigo } \\
\text { Wheat meal }\end{array}$ & $\mathrm{kg}$ & 21,20 \\
\hline $\begin{array}{l}\text { Feno de alfafa } \\
\text { Alfalfa hay }\end{array}$ & $\mathrm{kg}$ & 15,00 \\
\hline $\begin{array}{l}\text { Feno de aveia } \\
\text { Oat hay }\end{array}$ & $\mathrm{kg}$ & 15,00 \\
\hline $\begin{array}{l}\text { Casca de arroz } \\
\text { Rice hulls }\end{array}$ & $\mathrm{kg}$ & 5,00 \\
\hline $\begin{array}{l}\text { Sal } \\
\text { Salt }\end{array}$ & $\mathrm{kg}$ & 0,40 \\
\hline $\begin{array}{l}\text { Fosfato bicácico } \\
\text { Dicalcium phosphate }\end{array}$ & $\mathrm{kg}$ & 1,00 \\
\hline $\begin{array}{l}\text { Calcário } \\
\text { Limestone }\end{array}$ & $\mathrm{kg}$ & 1,00 \\
\hline $\begin{array}{l}\text { Bacitracina de zinco } \\
\text { Zinc bacitracine }\end{array}$ & $\mathrm{kg}$ & 0,05 \\
\hline $\begin{array}{l}\text { Coccidiostático } \\
\text { Coccidiostat }\end{array}$ & $\mathrm{kg}$ & 0,06 \\
\hline $\begin{array}{l}\text { DL-Metionina } \\
\text { DL-Methionine }\end{array}$ & $\mathrm{kg}$ & 0,10 \\
\hline $\begin{array}{l}\text { Mist. Vit+Min }{ }^{1} \\
\text { Vitamin and trace } \\
\text { mineral suplement }{ }^{1}\end{array}$ & $\mathrm{~kg}$ & 1,00 \\
\hline $\begin{array}{l}\text { Matéria seca } \\
\text { Dry matter }\end{array}$ & $(\%)$ & 89,33 \\
\hline $\begin{array}{l}\text { Proteína bruta } \\
\text { Crude protein }\end{array}$ & $(\%)$ & 15,27 \\
\hline $\begin{array}{l}\text { Fibra bruta } \\
\text { Crude fiber }\end{array}$ & $(\%)$ & 15,21 \\
\hline $\begin{array}{l}\text { FDN } \\
N D F\end{array}$ & $(\%)$ & 41,71 \\
\hline $\begin{array}{l}\text { FDA } \\
A D F\end{array}$ & $(\%)$ & 23,28 \\
\hline $\begin{array}{l}\text { Energia bruta } \\
\text { Gross energy }\end{array}$ & $\mathrm{kcal} / \mathrm{kg}$ & 4397 \\
\hline
\end{tabular}

${ }^{1}$ Nuvital, composição por kg do produto (composition per kg): Vit A, $300.000 \mathrm{UI}$; Vit D, $50.000 \mathrm{UI}$; Vit E, $4000 \mathrm{mg}$; Vit $\mathrm{K}_{3}, 100 \mathrm{mg}$ Vit $B_{1}, 200 \mathrm{mg} ;$ Vit $B_{2}, 300 \mathrm{mg} ;$ Vit $B_{6}, 100 \mathrm{mg} ;$ Vit $B_{12}, 1000 \mathrm{mcg}$; Ac. nicotínico (Nicotinic acid), $1500 \mathrm{mg}$; Ac. pantotênico (Panthotenic acid), $1000 \mathrm{mg}$; Colina (Choline), $35.000 \mathrm{mg}$; Fe, $4000 \mathrm{mg}$; Cu, $600 \mathrm{mg}$; Co, $100 \mathrm{mg}$; Mn, $4300 \mathrm{mg}$; Zn, $6000 \mathrm{mg} ; \mathrm{I}, 32 \mathrm{mg}$; Se, $8 \mathrm{mg}$; Met, $60.000 \mathrm{mg}$; Promotor de crescimento (Growth promoter), 1500 mg; Coccidiostático (Coccidiostat), 12.500 mg; Antioxidante (Sinox), $10.000 \mathrm{mg}$.

\section{Resultados e Discussão}

Os coeficientes de digestibilidade aparente da MS, PB, FB e EB da LRRR e LRSD encontram-se na Tabela 3.

Não foram observadas diferenças $(\mathrm{P}>0,05)$ sobre os coeficientes de digestibilidade aparentes da matéria seca e fibra bruta entre as leveduras. Entretanto, a LRSD foi a que apresentou os maiores coeficientes de digestibilidade aparente $(\mathrm{P}<0,05)$ para proteína bruta e energia bruta. $\mathrm{O}$ valor encontrado para digestibilidade aparente da proteína bruta da LRSD neste experimento foi semelhante ao obtido por COZZOLINO (1982), trabalhando com ratos. Valores mais elevados no coeficiente de digestibilidade da proteína da levedura que os observados neste experimento foram obtidos por BATTISTI et al. (1985), trabalhando com suínos em acabamento, e FAZANO (1986), trabalhando com coelhos em crescimento. O coeficiente de digestibilidade aparente da proteína da levedura obtido por FIALHO et al. (1985), com suínos em acabamento, foi inferior ao obtido para LRSD, mas superior ao da LRRR neste experimento. O coeficiente de digestibilidade obtido por esses autores, no entanto, foi melhor que o obtido no presente trabalho para LRRR. Os resultados de trabalhos conduzidos por FAZANO (1986) e SCAPINELLO et al. (1995), avaliando o valor nutritivo do farelo de soja, utilizado como principal fonte de proteína para rações de coelhos, mostram grande proximidade aos resultados de disponibilidade de nutrientes das leveduras, especialmente para LRSD.

As diferenças encontradas entre as leveduras, em que a LRSD apresentou maior valor nutritivo, podem estar associadas ao processo de secagem, em que o método spray-dry apresentou maior temperatura $\left(200-250^{\circ} \mathrm{C}\right)$ que o sistema rolo rotativo $(100$ $128^{\circ} \mathrm{C}$ ). O tempo de exposição da levedura a essas temperaturas foi menor no primeiro processo de secagem. Possivelmente, como as origens da LRRR e LRSD foram diferentes, outros fatores além dos

Tabela 3 - Coeficientes de digestibilidade aparente da MS, PB, FB e EB da levedura de recuperação (Saccharomyces $\mathrm{sp}$ ), seca por rolo rotativo (LRRR) ou por spray-dry (LRSD)

Table 3 - Coefficients of apparent digestibility of DM, CP, CF and GE of recovery yeast (Saccharomyces $s p$ ), dried by rotational cylinder (RYRC) or by spray-dry (RYSD)

\begin{tabular}{lcccc}
\hline $\begin{array}{l}\text { Nutrientes } \\
\text { Nutrient }\end{array}$ & $\begin{array}{c}\text { Unidade } \\
\text { Unit }\end{array}$ & $\begin{array}{c}\text { LRRR } \\
\text { RYRC }\end{array}$ & $\begin{array}{c}\text { LRSD } \\
\text { RYSD }\end{array}$ & CV\% \\
\hline $\begin{array}{l}\text { Matéria seca } \\
\text { Dry matter }\end{array}$ & $(\%)$ & $73,80^{\mathrm{A}}$ & $82,33^{\mathrm{A}}$ & 13,21 \\
$\begin{array}{l}\text { Proteína bruta } \\
\begin{array}{l}\text { Crude protein } \\
\text { Fibra bruta }\end{array}\end{array}$ & $(\%)$ & $55,44^{\mathrm{B}}$ & $79,14^{\mathrm{A}}$ & 13,88 \\
$\begin{array}{l}\text { Crude fibre } \\
\text { Energia bruta }\end{array}$ & $(\%)$ & $55,27^{\mathrm{A}}$ & $48,24^{\mathrm{A}}$ & 43,85 \\
& $(\%)$ & $69,60^{\mathrm{B}}$ & $87,19^{\mathrm{A}}$ & 15,99
\end{tabular}

Gross energy

Médias, na linha, seguidas com letras maiúscula diferente são diferentes $(P<0,05)$ pelo teste $F$.

Means, in a row, followed by different letters differ $(P<.05)$ by $F$ test. 
FARIA et al.

Tabela 4 - Matéria seca digestível (MSD), proteína digestível (PD), fibra digestível (FD) e energia digestível (ED) da levedura de recuperação (Saccharomyces sp), seca por rolo rotativo (LRRR) ou por spray-dry (LRSD), com base na matéria seca total

Table 4 - Digestible dry matter (DMD), digestible protein (DP), digestible fiber (DF) and digestible energy (DE) of recovery yeast (Saccharomyses $s p$ ), dried by rotational cylinder (RYRC) or by spray-dry (RYSD), \% DM

\begin{tabular}{lccc}
\hline $\begin{array}{l}\text { Nutrientes } \\
\text { Nutrients }\end{array}$ & $\begin{array}{c}\text { Unidade } \\
\text { Unit }\end{array}$ & $\begin{array}{c}\text { LRRR } \\
\text { RYRC }\end{array}$ & $\begin{array}{c}\text { LRSD } \\
\text { RYSD }\end{array}$ \\
\hline MSD & $(\%)$ & 68,06 & 75,57 \\
$D M D$ & $(\%)$ & 18,25 & 25,22 \\
PD & & & \\
$D P$ & $(\%)$ & 0,80 & 0,20 \\
FD & & & \\
$D F$ & $(\mathrm{kcal} / \mathrm{kg})$ & 3248 & 3859 \\
ED & & & \\
$D E$ & & &
\end{tabular}

citados, podem estar implicando nas diferenças de valor nutritivo entre as leveduras, como substrato, grau de aeração do meio, métodos de fermentação, idade das células ou número de lavagens sucessivas para eliminação de impurezas.

Os teores de nutrientes digestíveis obtidos para a LRRR e a LRSD, considerando os resultados da composição química das leveduras e os coeficientes de digestibilidade aparentes, são apresentados na Tabela 4.

Os resultados revelaram que os coelhos conseguem aproveitar com boa eficiência a fração nitrogenada e energética da levedura de destilarias de álcool, sendo que os melhores resultados foram obtidos para a LRSD.

\section{Conclusões}

Os coeficientes de digestibilidade aparente da matéria seca, proteína bruta, fibra bruta e energia bruta foram, respectivamente, de $73,80 \%, 55,44 \%, 55,27 \%$ e $69,60 \%$ para a levedura de recuperação seca em rolo rotativo (LRRR) e de 82,$33 ; 79,14 ; 48,24$; e $87,19 \%$ para a levedura de recuperação seca por spray-dry (LRSD). Os teores de matéria seca digestível (MSD), proteína digestível (PD), fibra digestível (FD) e energia digestível (ED) foram, respectivamente, de $68,06 \%$, $18,25 \%, 0,80 \%$ e $3248 \mathrm{kcal} / \mathrm{kg}$ para a levedura de recuperação seca em rolo rotativo (LRRR) e de $75,57 \%, 25,22 \%, 0,20 \%$ e $3859 \mathrm{kcal} / \mathrm{kg}$ para levedura de recuperação seca por spray-dry (LRSD).

A levedura de recuperação, seca pelo método spray-dry, foi nutricionalmente melhor que aquela seca em rolo rotativo, para coelhos em crescimento.

\section{Referências Bibliográficas}

BATTISTI, J.A., PEREIRA, J.A.A., COSTA, P.M.A. et al. 1985 Composição química e valores energéticos de alguns alimentos para suínos com diferentes idades. R. Bras. Zootec., 14 (2):141-150.

CARREGAL, R.D., FONSECA, T.Z. 1990. Substituição parcial e total da proteína do farelo de soja pela proteína da levedura seca em rações para coelhos em crescimento. R. Bras. Zootec., 19(3):197-200

CARREGAL, R.D., JACOB, D.V., RESENDE, K.T. et al. 1990. Avaliação do valor nutritivo do farelo de soja e da levedura seca através da digestibilidade aparente com coelhos. In: REUNIÃO ANUAL DA SOCIEDADE BRASILEIRA DE ZOOTECNIA, 27, 1990. Campinas. Anais... Campinas, SBZ, 1990. p.212.

COZZOLINO, S.M.F. Valor nutricional da biomassa de Saccharomyces cerevisiae. Estudos em gerações sucessivas de ratos. São Paulo, SP: USP, 1982. 147p. (Tese de Doutorado) - Faculdade de Ciências Farmacêuticas/USP, 1982.

DABBAH, P.R. 1970. Protein from microorganism. Food Technology, 24(6):659-666.

FAZANO, A.R.T. Digestibilidade e valor biológico da proteína da levedura seca (Saccharomyces sp) e do farelo de soja para coelhos. Piracicaba, SP: ESALQ/USP, 1986. 64p. (Dissertação de Mestrado) - Escola Superior de Agricultura Luiz de Queiroz, 1986.

FIALHO, E.T., ALBINO, L.F.T., BLUME, E. 1985. Composição química e valores energéticos de alguns alimentos para suínos. Pesq. Agropec. Bras., 20(12):1419-1431.

KIHLBERG, R. 1972. The microbe as a source of food. Annual Rev. Microb. 26(8):428-466.

MATTERSON, L.D., POTTER, L.M., SINGSEN, E.P. 1965. The metabolizable energy of feed ingredients for chickens. Research Report., 7:3-11.

MIYADA, V.S. A levedura seca na alimentação de suínos. Estudos adicionais sobre o seu valor protéico e vitamínico. Piracicaba, SP: ESALQ/USP, 1987. 139p. (Tese de Doutorado) - Escola Superior de Agricultura Luiz de Queiroz, 1987.

PROENÇA, C.E.M., MOURA, A.S.A.M.T., POLASTRE, R. et al. Efeito da levedura de álcool na ração sobre o desempenho ponderal de coelhos. In: REUNIAO ANUAL DA SOCIEDADE BRASILEIRA DE ZOOTECNIA, 19, 1982, Piracicaba. Anais... Piracicaba: SBZ, 1982. p.249.

SCAPINELLO, C., TAFURI, M.L., ROSTAGNO, H.S. et al. 1995. Valor nutritivo do milho, do farelo de soja e do feno de aveia para coelhos em crescimento. R. Bras. Zootec., 24(6):1001-1007.

SILVA, D.J. 1990. Análise de alimentos (métodos químicos e biológicos). 2 ed. Viçosa, UFV: Impr. Univ. 165p.

YUORSI, R.F. 1982. Single cell protein: its potential use for animal and human nutrition. W. Rev. Anim. Prod., 18(2):49-67.

Recebido em: 08/02/00

Aceito em: 25/05/00 